\title{
IAEA coordinated research programme: nuclear data for the production of therapeutic radionuclides
}

\author{
R. Capote ${ }^{1, a}$, E. Běták ${ }^{2}$, B.V. Carlson ${ }^{3}$, H.D. Choi $^{4}$, A. Ignatyuk ${ }^{5}$, E. Menapace ${ }^{6}$, F.M. Nortier ${ }^{7}$, S.M. Qaim ${ }^{8}$, B. Scholten ${ }^{8}$, \\ Y.N. Shubin ${ }^{5} \dagger$, J.C. Sublet ${ }^{9}$, and F.T. Tarkanyi ${ }^{10}$ \\ 1 Nuclear Data Section, International Atomic Energy Agency, 1400 Vienna, Austria \\ 2 Institute of Physics, Slovak Academy of Science, 84511 Bratislava, Slovakia \\ 3 Instituto Tecnológico de Aeronáutica, 12228-900 São Jose dos Campos SP, Brazil \\ ${ }^{4}$ Department of Nuclear Engineering, Seoul National University, Seoul 151-744, Korea \\ 5 Institute of Physics and Power Engineering, 249020 Obninsk, Russian Federation \\ 6 ENEA - Applied Physics Division, C.R. "E. Clementel”, 40138 Bologna, Italy \\ 7 Los Alamos National Laboratory, Inorganic and Isotopes Chemistry Group, NM 7545, USA \\ 8 Institut für Nuklearchemie, Forschungszentrum Jülich GmbH, 52425 Jülich, Germany \\ 9 CEA Cadarache, 13108 Saint-Paul-lez-Durance Cedex, France \\ ${ }^{10}$ Cyclotron Department, Institute of Nuclear Research of the Hungarian Academy of Sciences, 4001 Debrecen, Hungary
}

\begin{abstract}
The need for radioisotopes in cancer therapy is very well established. With a view to providing standardised data for the production of relevant radioisotopes an IAEA Coordinated Research Project on "Nuclear Data for the Production of Therapeutic Radionuclides" was started in 2003, and is now close to completion. Experimental data compilations, theoretical calculations and evaluations were carried out for each of the reactions. The recommendations for both established and emerging radionuclides are discussed. Examples of the analyses carried out to produce the recommended data for some radionuclides are also presented. The improved quality of the nuclear data will make reactor and accelerator production of therapeutic radionuclides much more efficient and effective, and should also enhance their quality through improved purity.
\end{abstract}

\section{Introduction}

Cancer management is a major medical and economical issue because of the increasing incidence of the disease in the entire world. The increasing need of radioisotopes for medical applications related to cancer is very well established. There is a significant number of radioisotopes in use or being proposed for medical applications. The role of nuclear data is mainly with respect to ensuring the quality assurance of the produced radioactive materials and for optimisation of production routes [1]. Generally, the radionuclides used in radiotherapy possess particular decay characteristics - lowenergy $\alpha, \beta^{-}$and Auger electron emitters. While effective in therapeutic treatments, these somewhat elusive decay characteristics can create difficulties when using such properties to determine their production cross sections to ensure a pure radionuclidic product. While the therapeutic properties of specific radionuclides have been demonstrated in various medical trials and they can be produced in sufficient quantities, knowledge of their production reaction cross sections was poorly defined [2].

Additional motivation for nuclear data studies for medical applications is provided by the fact that cyclotrons and accelerators, available in recent years in an increasing number of countries, are being used for the production of radioisotopes for both diagnostic and therapeutic purposes. Reactors are still widely employed to produce radioisotopes for many different applications. Finally, it should be also noted that studies of

\footnotetext{
a Presenting author, e-mail: r.capotenoy@iaea.org $\dagger$ Deceased
}

nuclear reactions in the low and intermediate energy regions up to $200 \mathrm{MeV}$ are of considerable importance for testing nuclear models and for practical applications.

Those needs were addressed by IAEA through a Coordinated Research Projects (CRP). The CRP on nuclear data for diagnostic radionuclides was completed in 2001 [3] and the data are available through an IAEA Web site (http://wwwnds.iaea.org/medical/), while the equivalent therapeutic work is the subject of the present contribution.

Lists of the therapeutic radionuclides and their production reactions under study are given in tables 1 and 2, based on two categories:

Therapeutic radionuclides that have proven clinical uses Established Radionuclides;

Less-commonly used but potentially important radionuclides for which medical applications have been demonstrated - Emerging Radionuclides.

Experimental data compilations and data selection, theoretical calculations using different modelling codes and the final evaluations for each of the reactions producing therapeutic radionuclides have been undertaken. We have considered in our study both neutron and charged-particle induced reactions. Neutron induced reactions $(n, \gamma),(n, f)$ and $(n, p)$ are used for radionuclide production in nuclear reactors, while chargedparticle induced reactions with incident proton, deuteron, ${ }^{3} \mathrm{He}$ and alpha particles have been used for radioisotope production in particle accelerators. Some examples are presented in the following sections. 
Table 1. Established therapeutic radionuclides.

\begin{tabular}{|c|c|c|}
\hline Nuclide & Production Route & $\mathbf{R} / \mathbf{A}$ \\
\hline \multirow[t]{2}{*}{${ }^{32} \mathrm{P}$} & ${ }^{31} \mathrm{P}(\mathrm{n}, \gamma)$ & $\mathrm{R}$ \\
\hline & ${ }^{32} \mathrm{~S}(\mathrm{n}, \mathrm{p})$ & $\mathrm{R}, \mathrm{A}$ \\
\hline \multirow[t]{2}{*}{${ }^{89} \mathrm{Sr}$} & ${ }^{88} \operatorname{Sr}(\mathrm{n}, \gamma)$ & $\mathrm{R}$ \\
\hline & ${ }^{89} \mathrm{Y}(\mathrm{n}, \mathrm{p})$ & $\mathrm{R}, \mathrm{A}$ \\
\hline \multirow[t]{3}{*}{${ }^{90} \mathrm{Y}$} & ${ }^{235} \mathrm{U}(\mathrm{n}, \mathrm{f}){ }^{90} \mathrm{Sr} \rightarrow{ }^{90} \mathrm{Y}$ generator & $\mathrm{R}$ \\
\hline & ${ }^{89} \mathrm{Y}(\mathrm{n}, \gamma)$ & $\mathrm{R}$ \\
\hline & ${ }^{90} \mathrm{Zr}(\mathrm{n}, \mathrm{p})$ & $\mathrm{R}$ \\
\hline \multirow[t]{3}{*}{${ }^{103} \mathrm{Pd}$} & ${ }^{102} \operatorname{Pd}(\mathrm{n}, \gamma)$ & $\mathrm{R}$ \\
\hline & ${ }^{103} \mathrm{Rh}(\mathrm{p}, \mathrm{n})$ & A \\
\hline & ${ }^{103} \mathrm{Rh}(\mathrm{d}, 2 \mathrm{n})$ & A \\
\hline \multirow[t]{3}{*}{${ }^{125} \mathrm{I}$} & ${ }^{124} \mathrm{Xe}(\mathrm{n}, \gamma){ }^{125} \mathrm{Xe} \rightarrow{ }^{125} \mathrm{I}$ & $\mathrm{R}$ \\
\hline & ${ }^{124} \mathrm{Te}(\mathrm{d}, \mathrm{n})$ & A \\
\hline & ${ }^{125} \mathrm{Te}(\mathrm{p}, \mathrm{n})$ & A \\
\hline \multirow[t]{2}{*}{${ }^{131} \mathrm{I}$} & ${ }^{130} \mathrm{Te}(\mathrm{n}, \gamma){ }^{131} \mathrm{Te} \rightarrow{ }^{131} \mathrm{I}$ & $\bar{R}$ \\
\hline & ${ }^{235} \mathrm{U}(\mathrm{n}, \mathrm{f})$ & $\mathrm{R}$ \\
\hline${ }^{137} \mathrm{Cs}$ & ${ }^{235} \mathrm{U}(\mathrm{n}, \mathrm{f})$ & $\mathrm{R}$ \\
\hline \multirow[t]{2}{*}{${ }^{153} \mathrm{Sm}$} & ${ }^{152} \mathrm{Sm}(\mathrm{n}, \gamma)$ & $\mathrm{R}$ \\
\hline & ${ }^{153} \mathrm{Eu}(\mathrm{n}, \mathrm{p})$ & $\mathrm{R}, \mathrm{A}$ \\
\hline \multirow[t]{3}{*}{${ }^{186} \operatorname{Re}$} & ${ }^{185} \operatorname{Re}(\mathrm{n}, \gamma)$ & $\mathrm{R}$ \\
\hline & ${ }^{186} \mathrm{~W}(\mathrm{p}, \mathrm{n})$ & A \\
\hline & ${ }^{186} \mathrm{~W}(\mathrm{~d}, 2 \mathrm{n})$ & A \\
\hline \multirow[t]{2}{*}{${ }^{188} \mathrm{Re}$} & $\begin{array}{l}{ }^{186} \mathrm{~W}(\mathrm{n}, \gamma) \rightarrow{ }^{187} \mathrm{~W}(\mathrm{n}, \gamma)^{188} \mathrm{~W} \\
\rightarrow{ }^{188} \mathrm{Re} \text { generator }\end{array}$ & $\mathrm{R}$ \\
\hline & ${ }^{187} \operatorname{Re}(\mathrm{n}, \gamma)$ & $\mathrm{R}$ \\
\hline \multirow[t]{3}{*}{${ }^{192} \mathrm{Ir}$} & ${ }^{191} \operatorname{Ir}(\mathrm{n}, \gamma)$ & $\mathrm{R}$ \\
\hline & ${ }^{192} \mathrm{Os}(\mathrm{p}, \mathrm{n})$ & A \\
\hline & ${ }^{192} \mathrm{Os}(\mathrm{d}, 2 \mathrm{n})$ & A \\
\hline
\end{tabular}

\section{Neutron induced reactions}

Neutron induced reactions have been used for production of therapeutic radionuclides ${ }^{32} \mathrm{P},{ }^{105} \mathrm{Rh},{ }^{131} \mathrm{I}$ and ${ }^{192} \mathrm{Ir}$ in nuclear reactors. Three of these isotopes, namely ${ }^{32} \mathrm{P},{ }^{131} \mathrm{I}$ and ${ }^{192} \mathrm{Ir}$ are radioisotopes in routine clinical use while ${ }^{105} \mathrm{Rh}$, a $\beta^{-}$decaying transition metal, is included in the study as one of potential emerging isotopes for medical applications. As a typical example we selected the very well established radionuclide ${ }^{131} \mathrm{I}$, which is produced either as a fission product of the ${ }^{235} \mathrm{U}$ burnt in reactor or by using the capture reaction ${ }^{130} \mathrm{Te}(\mathrm{n}, \gamma){ }^{131} \mathrm{Te}$.

${ }^{131} \mathrm{I}$ is a $100 \% \beta^{-}$-decaying isotope with a half-life of $8.0207(1)$ days. Both the ground and isomeric states of the isotope ${ }^{131} \mathrm{Te}$ are populated in the capture reaction. The isomeric state ${ }^{131 \mathrm{~m}} \mathrm{Te}\left(182.25 \mathrm{keV}, 11 / 2^{-}\right)$has a half-life of 30 hours, considerably longer than the 25 min corresponding to the ground state ${ }^{131 \mathrm{~g}} \mathrm{Te}\left(3 / 2^{+}\right)$.

The evaluated cross sections for neutron induced reactions on ${ }^{130} \mathrm{Te}$ are shown in figure 1 (see next page). Reasonable agreement with the available experimental data has been obtained with special emphasis in describing the capture reaction below $1 \mathrm{MeV}$. Employed methodology will be described in the final technical report of the CRP.

\section{Charged-particle induced reactions}

Iodine-124 is one of the most important emerging therapeutic radionuclides. Its decay characteristics support a combination of therapy and positron emission tomography, allowing
Table 2. Emerging therapeutic radionuclides.

\begin{tabular}{|c|c|c|}
\hline Nuclide & Production route & R/A/D \\
\hline \multirow[t]{6}{*}{${ }^{64} \mathrm{Cu}$} & ${ }^{63} \mathrm{Cu}(\mathrm{n}, \gamma)$ & $\bar{R}$ \\
\hline & ${ }^{64} \mathrm{Ni}(\mathrm{p}, \mathrm{n})$ & A \\
\hline & ${ }^{64} \mathrm{Ni}(\mathrm{d}, 2 \mathrm{n})$ & A \\
\hline & ${ }^{68} \mathrm{Zn}(\mathrm{p}, \mathrm{x})$ & A \\
\hline & $\mathrm{Zn}(\mathrm{d}, \mathrm{x})$ & A \\
\hline & ${ }^{64} \mathrm{Zn}(\mathrm{n}, \mathrm{p})$ & $\mathrm{R}$ \\
\hline \multirow[t]{3}{*}{${ }^{67} \mathrm{Cu}$} & ${ }^{67} \mathrm{Zn}(\mathrm{n}, \mathrm{p})$ & $\mathrm{R}$ \\
\hline & ${ }^{68} \mathrm{Zn}(\mathrm{p}, 2 \mathrm{p})$ & A \\
\hline & ${ }^{70} \mathrm{Zn}(\mathrm{p}, \alpha)$ & A \\
\hline${ }^{67} \mathrm{Ga}$ & ${ }^{68} \mathrm{Zn}(\mathrm{p}, 2 \mathrm{n}),{ }^{67} \mathrm{Zn}(\mathrm{p}, \mathrm{n})$ & A \\
\hline${ }^{86} \mathrm{Y}$ & ${ }^{86} \mathrm{Sr}(\mathrm{p}, \mathrm{n})$ & A \\
\hline${ }^{105} \mathrm{Rh}$ & ${ }^{104} \mathrm{Ru}(\mathrm{n}, \gamma){ }^{105} \mathrm{Ru} \rightarrow{ }^{105} \mathrm{Rh}$ & $\mathrm{R}$ \\
\hline${ }^{111}$ In & ${ }^{111} \mathrm{Cd}(\mathrm{p}, \mathrm{n}),{ }^{112} \mathrm{Cd}(\mathrm{p}, 2 \mathrm{n})$ & A \\
\hline \multirow[t]{4}{*}{${ }^{114 m}$ In } & ${ }^{113} \operatorname{In}(\mathrm{n}, \gamma)$ & $\mathrm{R}$ \\
\hline & ${ }^{114} \mathrm{Cd}(\mathrm{p}, \mathrm{n})$ & A \\
\hline & ${ }^{116} \mathrm{Cd}(\mathrm{p}, 3 \mathrm{n})$ & A \\
\hline & ${ }^{114} \mathrm{Cd}(\mathrm{d}, 2 \mathrm{n})$ & A \\
\hline \multirow[t]{3}{*}{${ }^{124} \mathrm{I}$} & ${ }^{124} \mathrm{Te}(\mathrm{p}, \mathrm{n})$ & A \\
\hline & ${ }^{124} \mathrm{Te}(\mathrm{d}, 2 \mathrm{n})$ & A \\
\hline & ${ }^{125} \mathrm{Te}(\mathrm{p}, 2 \mathrm{n})$ & A \\
\hline${ }^{149} \mathrm{Pm}$ & ${ }^{148} \mathrm{Nd}(\mathrm{n}, \gamma){ }^{149} \mathrm{Nd} \rightarrow{ }^{149} \mathrm{Pm}$ & $\mathrm{R}$ \\
\hline \multirow[t]{2}{*}{${ }^{166} \mathrm{Ho}$} & ${ }^{165} \mathrm{Ho}(\mathrm{n}, \gamma)$ & $\overline{\mathrm{R}}$ \\
\hline & $\begin{array}{l}{ }^{164} \mathrm{Dy}(\mathrm{n}, \gamma) \rightarrow{ }^{165} \mathrm{Dy}(\mathrm{n}, \gamma) \rightarrow \\
{ }^{166} \mathrm{Dy} \rightarrow{ }^{166} \mathrm{Ho}\end{array}$ & $\mathrm{R}$ \\
\hline \multirow[t]{3}{*}{${ }^{169} \mathrm{Yb}$} & ${ }^{168} \mathrm{Yb}(\mathrm{n}, \gamma)$ & $\mathrm{R}$ \\
\hline & ${ }^{169} \operatorname{Tm}(\mathrm{p}, \mathrm{n})$ & A \\
\hline & ${ }^{169} \operatorname{Tm}(d, 2 n)$ & A \\
\hline \multirow[t]{3}{*}{${ }^{177} \mathrm{Lu}$} & ${ }^{176} \mathrm{Yb}(\mathrm{n}, \gamma){ }^{177} \mathrm{Yb} \rightarrow{ }^{177} \mathrm{Lu}$ & $\mathrm{R}$ \\
\hline & ${ }^{176} \mathrm{Lu}(\mathrm{n}, \gamma)$ & $\mathrm{R}$ \\
\hline & ${ }^{176} \mathrm{Yb}(\mathrm{d}, \mathrm{x})$ & A \\
\hline${ }^{211} \mathrm{At}$ & ${ }^{209} \mathrm{Bi}(\alpha, 2 \mathrm{n})$ & A \\
\hline${ }^{213} \mathrm{Bi}$ & decay of ${ }^{225} \mathrm{Ac}$ & Decay \\
\hline \multirow[t]{2}{*}{${ }^{225} \mathrm{Ac}$} & ${ }^{226} \mathrm{Ra}(\mathrm{p}, 2 \mathrm{n})$ & A \\
\hline & decay of ${ }^{233} \mathrm{U} \rightarrow{ }^{229} \mathrm{Th}$ & R, Decay \\
\hline
\end{tabular}

accurate local dosimetry. As a result ${ }^{124} \mathrm{I}$ is considered to be a superior therapeutic agent over the commonly used reactor produced ${ }^{131} \mathrm{I}$. Two of the considered reactions for ${ }^{124} \mathrm{I}$ production, ${ }^{124} \mathrm{Te}(\mathrm{d}, 2 \mathrm{n}){ }^{124} \mathrm{I}$ and ${ }^{125} \mathrm{Te}(\mathrm{p}, 2 \mathrm{n}){ }^{124} \mathrm{I}$, are discussed below.

\subsection{Deuteron induced reaction: ${ }^{124} \mathrm{Te}(\mathrm{d}, 2 \mathrm{n})^{124}$ I}

The ${ }^{124} \mathrm{Te}(\mathrm{d}, 2 \mathrm{n}){ }^{124} \mathrm{I}$ reaction was originally used for the production of ${ }^{124} \mathrm{I}$. Two experimental cross section data sets for this reaction are available in the literature $[4,5]$. The original cross-section values published by Firouzbakht et al. [5] were incorrect. New cross sections were recalculated from the authors' thin target yield values presented in the same paper. Newly derived data compare very well with those of Bastian et al. [4]. In figure 2 experimental data sets are compared with theoretical curves. All theoretical calculations are higher by about a factor of 2 in the peak area. This could be partly due to the fact that the deuteron break-up channel is not properly considered; however this is a clear indication that we should improve our theoretical modeling of deuteron induced reactions. Such differences between theoretical calculations 


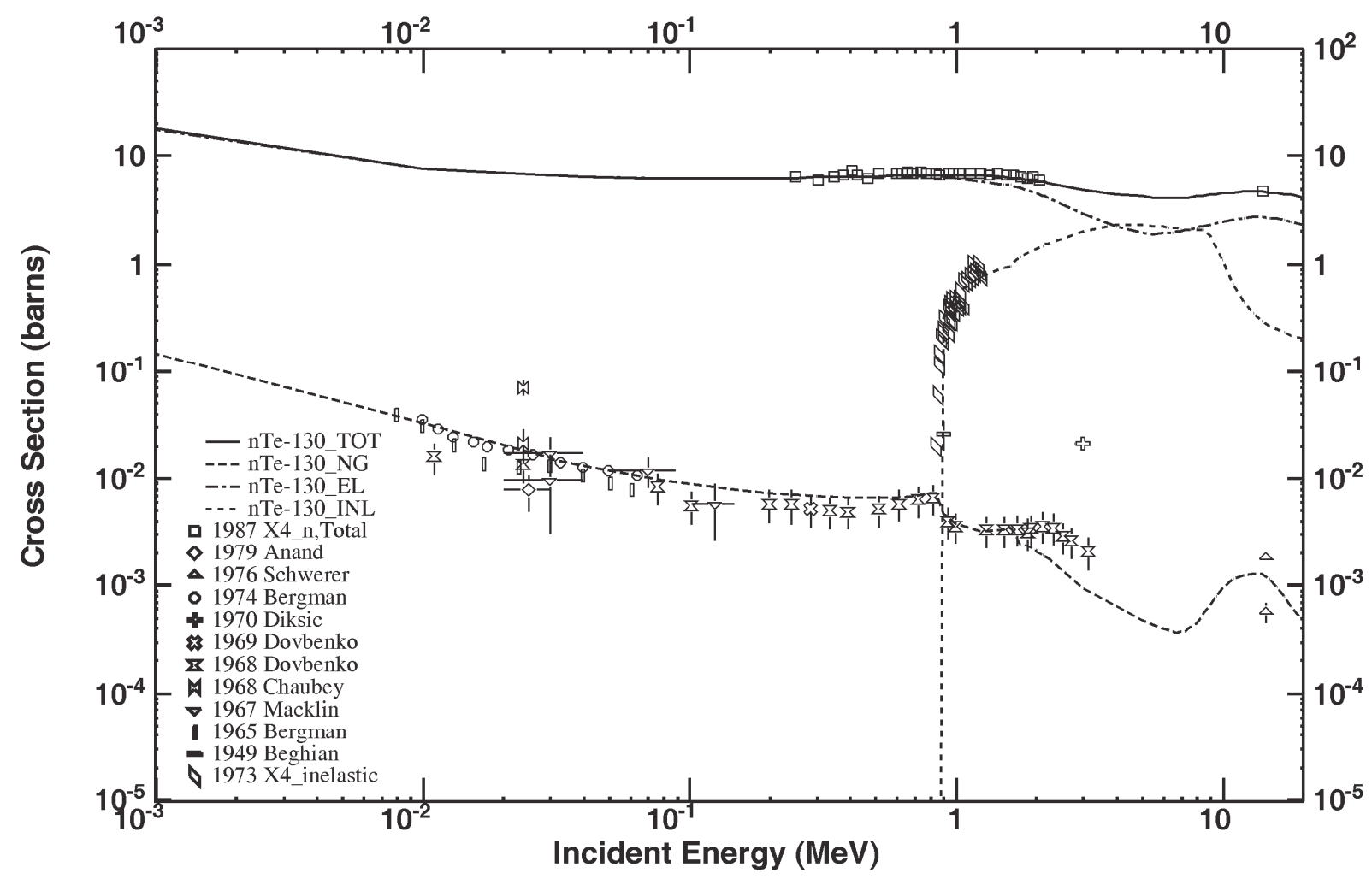

Fig. 1. Selected neutron induced reactions on ${ }^{130} \mathrm{Te}$ up to $20 \mathrm{MeV}$. Cross sections $\sigma_{\text {tot }}(\mathrm{E}), \sigma_{\mathrm{el}}(\mathrm{E}), \sigma_{\text {inel }}(\mathrm{E})$ and $\sigma(\mathrm{n}, \gamma)$ are shown in continuous, dot-dashed, dotted and dashed line, respectively.

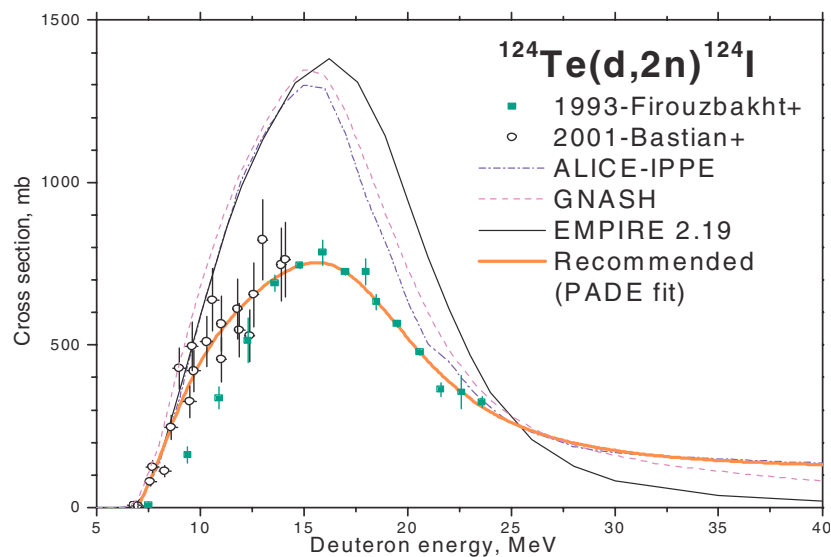

Fig. 2. ${ }^{124} \mathrm{I}$ production by deuteron induced reaction on ${ }^{124} \mathrm{Te}$.

and experimental data were observed for all deuteron induced reactions. Recommended data obtained by a well established Padé fit is also shown in the figure.

The user should be aware that ${ }^{125} \mathrm{I}$ is also produced as an impurity in this reaction. In order to determine such impurity levels the ${ }^{124} \mathrm{Te}(\mathrm{d}, \mathrm{n}){ }^{125} \mathrm{I}$ reaction has also been evaluated. Thin target yields were calculated from the cross sections reported by Bastian et al. [5] and yield ratios derived. It became clear that production at energies below $11 \mathrm{MeV}$ should be avoided.

\subsection{Proton induced reaction: ${ }^{125} \mathrm{Te}(\mathrm{p}, 2 \mathrm{n})^{124} \mathrm{I}$}

${ }^{125} \mathrm{Te}(\mathrm{p}, 2 \mathrm{n}){ }^{124} \mathrm{I}$ reaction is another possible production route which seems to be the best from a yield point of view. Only

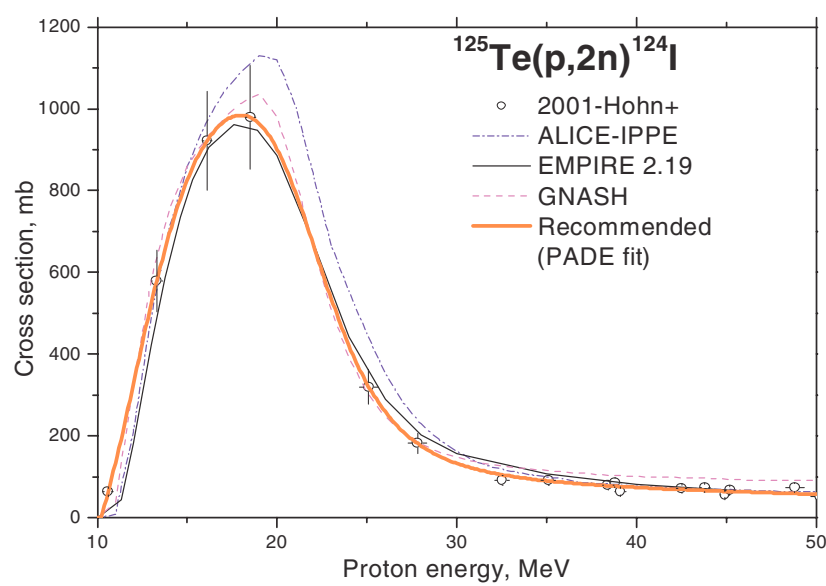

Fig. 3. ${ }^{124} \mathrm{I}$ production by proton induced reaction on ${ }^{125} \mathrm{Te}$.

one set of experimental data reported by Hohn et al [6] exists in the energy range up to $100 \mathrm{MeV}$. Measured data are supported very well by theoretical calculations using ALICE, EMPIRE and GNASH codes for proton induced reactions.

Figure 3 shows the good agreement between the theoretical curves and the experimental measurements for this particular reaction. Recommended data is also given. In a further validation attempt as part of the present evaluation, thick target yields were also calculated from the experimental cross sections and are compared in figure 4 with the only thick target yield measurements found in the literature [7]. The obvious discrepancy shows that the validation effort is inconclusive. Nevertheless, the evaluator tends to favor the 


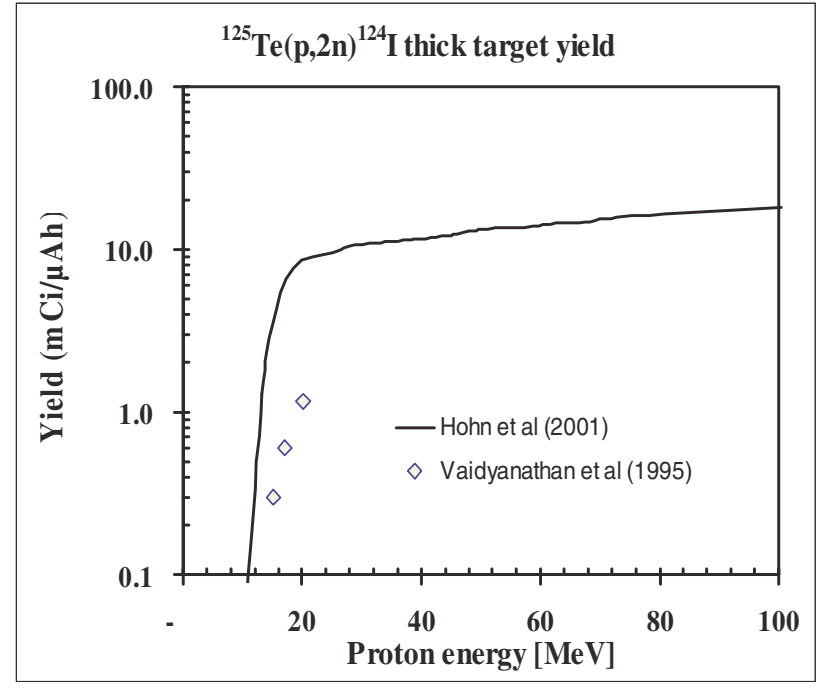

Fig. 4. Thick target yields for the ${ }^{125} \mathrm{Te}(\mathrm{p}, 2 \mathrm{n}){ }^{124} \mathrm{I}$ reaction.

data set reported by Hohn et al. [6] which is well supported by theory.

\subsection{Alpha induced reactions: ${ }^{209} \mathrm{Bi}(\alpha, 2 \mathrm{n})^{211} \mathrm{At}$}

The alpha-emitting isotope ${ }^{211}$ At is very much in demand but production and chemistry are difficult. New measurements show excellent agreement with older studies undertaken in 1949-1985 and also with theoretical calculations as can be seen in figure 5. One integral measurement has been completed in Ispra at $29 \mathrm{MeV}$ for this reaction showing a good agreement with the recommended cross-section data derived by Pade fit (thick red line in the fig. 5).

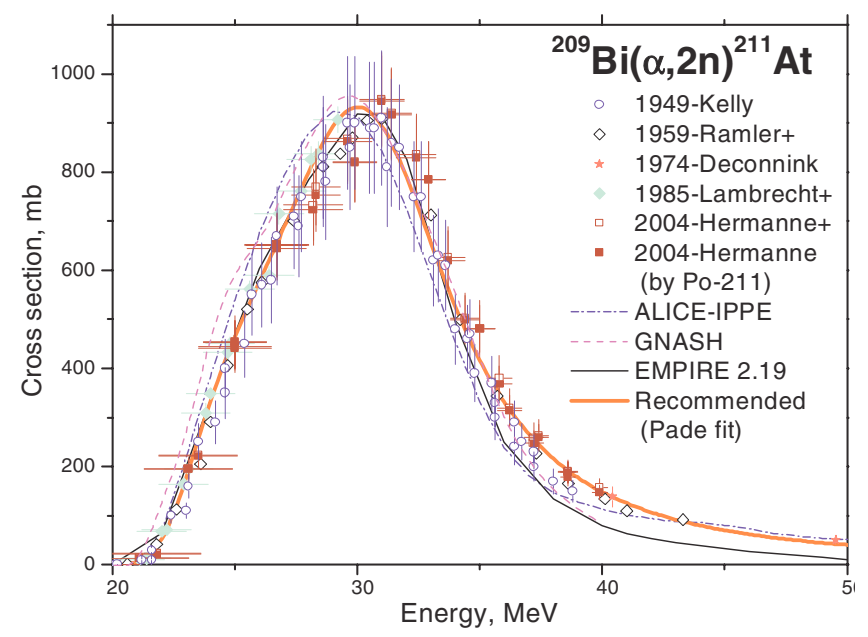

Fig. 5. Production of ${ }^{211}$ At radioisotope in $\alpha+{ }^{209} \mathrm{Bi}$ reaction.

The experimental cross-section data for the ${ }^{209} \mathrm{Bi}(\alpha, 3 \mathrm{n})$ reaction were also compiled and evaluation by Padé fitting made up to $70 \mathrm{MeV}$ as this reaction is important for characterising the impurity level, including the total ${ }^{210} \mathrm{Po}$ production. The evaluated data agree well with theoretical calculations up to $40 \mathrm{MeV}$ as shown in figure 6 .

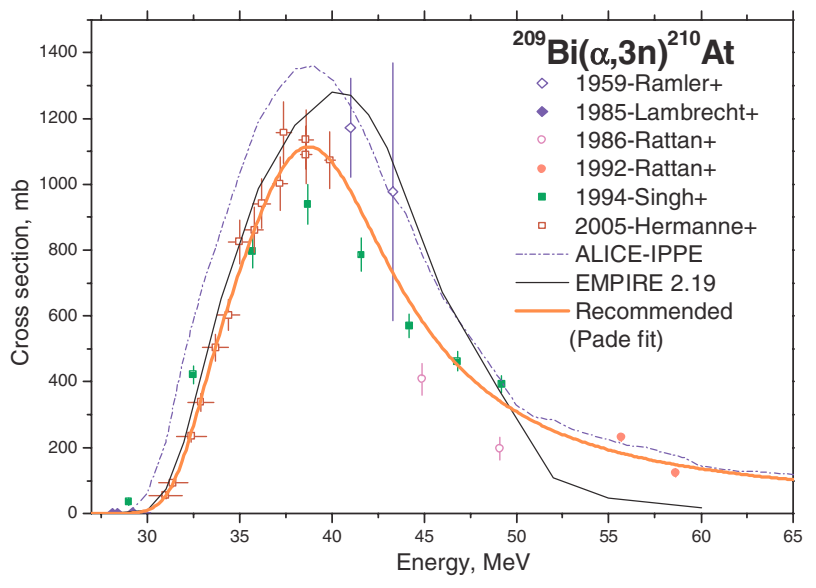

Fig. 6. Production of At-210 impurity in $\alpha+{ }^{209} \mathrm{Bi}$ reaction.

\section{Conclusions}

Experimental data compilations and data selection, theoretical calculations and the final evaluations for each of the reactions producing therapeutic radionuclides (see tables 1 and 2) have been carried out. The recommendations for both established and emerging therapeutic radionuclides, and validation/testing of the cross-section library should be available by the end of 2007. As a consequence of the work undertaken during the course of the two CRPs noted above, the resulting completeness and accuracy of the cross-section data for the production of these nuclides, along with a re-definition of their decay data, should be extremely beneficial in ensuring their safe and efficient application both in nuclear medicine and cancer therapy. Moreover, the data produced in the two CRPs will help to define strategies for the production of radioisotopes at cyclotrons, as is currently being studied by an expert group within the Industrial Applications and Chemistry Section of the IAEA Division of Physical and Chemical Sciences.

\section{References}

1. S.M. Qaim, Radiochim. Acta 89, 297 (2001).

2. INDC(NDS)-0423 Long term needs for nuclear data development (IAEA, Vienna, Austria, 2001).

3. IAEA-TECDOC-1211 Charged-particle cross-section database for medical radioisotope production: Diagnostic radioisotopes and monitor reactions (IAEA Vienna, Austria, 2001).

4. T. Bastian, H.H. Coenen, S.M. Qaim, Appl. Radiat. Isot. 55, 303 (2001).

5. M.L. Firouzbakht, D.J. Schlyer, R.D. Finn, G. Languzzi, A.P. Wolf, Nucl. Instrum. Meth. B 79, 909 (1993).

6. A. Hohn, F.M. Nortier, B. Scholten, T.N. van der Walt, H.H. Coenen, S.M. Qaim, Appl. Radiat. Isot. 55, 149 (2001).

7. G. Vaidyanathan, B.W. Wieland, R.H. Larsen, W.R. Zalutsky, J. Label. Comp. 37, 811 (1995). 